Don't forget to take a look at the interactive web version of the Report. Already, this contains more, and newer, information than the hard copy version, and it will be continually updated.

Finally, I congratulate everyone who contributed to the 2002 edition of the Report. I confidently predict that it will prove not only the biggest and best but also the most influential ever, through its support for evidence-based public health planning and practice.
Printed copies of the Health of the people of New South Wales-Report of the Chief Health Officer can be obtained from the Better Health Centre by telephone at (02) 98160452 or by facsimile at (02) 9816 0492. An electronic version, with downloaded data tables, is being continually updated and can be viewed at www.health.nsw.gov.au/public-health/chorep.

\title{
TRENDS IN POTENTIALLY AVOIDABLE MORTALITY IN NSW
}

\author{
Andrew Hayen, Doug Lincoln, and Helen Moore \\ Centre for Epidemiology and Research \\ NSW Department of Health
}

\section{Margaret Thomas \\ Centre for Health Promotion \\ NSW Department of Health}

In Australia, mortality rates, prevalence of health risk behaviours (such as smoking and inadequate physical activity), and prevalence of risk factors (such as obesity), have been shown to be significantly higher in lower socioeconomic (SES) groups than in higher SES groups. ${ }^{1}$ Similar inequalities in health have also been shown to exist in NSW. ${ }^{2}$

Avoidable mortality refers to deaths that potentially could be avoided either through prevention or through early medical intervention. ${ }^{3}$ To assess the potential effect of health interventions, it is useful to classify each condition that causes avoidable death according to the level of intervention (primary, secondary, and tertiary) to which that condition is responsive. Primary avoidable mortality (PAM) consists of conditions that are preventable by change in individual behaviour or through populationlevel interventions including healthy public policy that, for example, may result in introducing laws to reduce exposure to hazards, such as tobacco smoke. ${ }^{3}$

The study of inequalities in PAM allows an analysis of the effectiveness of primary level health interventions in different socioeconomic status groups and highlights conditions for which primary prevention approaches can potentially reduce inequalities. This article describes trends and differences in PAM by sex and socioeconomic status for some of the diseases and injuries that are amenable to primary prevention.

\section{METHODS}

Our analysis is based on death data for NSW for the period 1980-2000. All 'premature' deaths - that is, those that occur before 75 years of age-were classified into avoidable and unavoidable deaths, using the 9th revision of the International Classification of Diseases for deaths registered before 1999, and the 10 th revision of the International Classification of Diseases for deaths registered from 1999 onwards. ${ }^{4}$ Avoidable deaths were subcategorised using the algorithm of Tobias and Jackson, ${ }^{3}$ which divides all cases of each potentially avoidable condition into three groups. Cases are allocated to each group based on the evidence for the proportion that could potentially be prevented using primary, secondary, or tertiary interventions. The proportions for lung cancer are $0.95,0$ and 0.05 (for primary, secondary, and tertiary, respectively); for road traffic injury, they are $0.6,0$ and 0.4 respectively; and for ischaemic heart disease, they are $0.5,0.25$ and 0.25 respectively.

For example, for every 100 potentially avoidable deaths from ischaemic heart disease-where the proportions are $0.5,0.25$ and 0.25 respectively-it is estimated that 50 deaths could be avoided through primary interventions (for example, smoking cessation, improved diet, and increased physical activity); 25 deaths could be avoided through secondary interventions (lowering of cholesterol and blood pressure for those with early stage disease); and 25 deaths could be avoided through tertiary interventions (for example, angioplasties for those who have had heart attacks).

Socioeconomic (SES) groups were constructed using the Index of Relative Socioeconomic Disadvantage (IRSD), which is produced by the Australian Bureau of Statistics from census data. ${ }^{5}$ Each local government area in NSW was assigned an IRSD according to the socioeconomic characteristics of the area's residents such as income, occupation, education, non-English speaking background, and indigenous status.

Using the IRSD scores for the local government areas, the NSW population was split into three groups: the 'lowest' SES group, or the most disadvantaged 20 per cent of the population; the 'highest' SES group, or the least 
disadvantaged 20 per cent of the population; and the balance of the population, consisting of the middle 60 per cent of the population. IRSD scores from the 1986 census were used for the years 1980-1988; scores from the 1991 census were used for the years 1989-1993; and scores from the 1996 census were used for the years 19942000 .

For each socioeconomic group and potentially avoidable condition, age-standardised rates were calculated for the period 1980-2000, using the Australian population as at 30 June 1991 as the reference population. Additionally, Poisson regression models were used to assess changes in death rates by SES group, ${ }^{6}$ after adjusting for the effect of age.

\section{RESULTS}

Rates of PAM have decreased steeply for the three SES groups and for both sexes between 1980 and 2000 (Figure 1 ), with the rates decreasing by 51 per cent in males and 44 per cent in females between 1980 and 2000. However, the decrease has been more rapid for the highest SES group, which experienced a decrease of 60 per cent in PAM in males between 1980 and 2000, compared with the lowest and middle SES groups, which both experienced a decrease of about 50 per cent. For females, a similar pattern was observed, although the decrease was not as great, with decreases of 51 per cent (the highest SES), 42 per cent (the middle SES) and 45 per cent (the lowest SES).

The relative 'gap' in PAM between SES groups can be expressed as the percentage by which the PAM rate is higher in one SES group (for example, the lowest SES group) than in another SES group (for example, the highest SES group). The relative gap between groups was calculated using fitted values from Poisson regression models to enable identification of trends. Figure 2 shows that there was an increased relative gap between the highest SES group and the two lower SES groups between 1980 and 2000 for males and females. By contrast, the relative gap between the lowest and middle decreased slightly for males and remained almost constant for females between 1980 and 2000.

Ischaemic heart disease was the biggest contributor to PAM for all years between 1980 and 2000, accounting for 39 per cent of PAM in 1980 and 25 per cent of PAM in 2000. Rates of ischaemic heart disease decreased very steeply for males in all SES groups (see Figure 3). Rates also decreased for females in all SES groups, although the decrease was not as rapid as that observed for males (Figure 3 ). The relative gap between the highest and the lowest SES group, and between the highest and the middle SES group, also increased with time for both males and females (Figure 4). The gap between the middle and lowest SES groups remained almost constant between 1980 and 2000 for both males and females.
Lung cancer was the second biggest contributor to PAM for all years between 1980 and 2000, accounting for 21 per cent of PAM in 1980 and 35 per cent of PAM in 2000. Between 1980 and 2000, PAM for lung cancer decreased for males in all SES groups but increased slightly for females in the lowest and middle SES groups (Figure 5). The relative gap between the highest and the lowest SES group, and between the highest and the middle SES group, also increased with time for both males and females (Figure 6 ). The gap between the middle and lowest SES groups was almost constant between 1980 and 2000 for males and females.

Road traffic accidents were the third largest contributor to PAM in 1980, when they accounted for 15 per cent of primary avoidable deaths, and the fourth largest contributor to PAM in 2000, when they accounted for six per cent of primary avoidable deaths. PAM due to road traffic accidents decreased in all SES groups between 1980 and 2000, especially in males (Figure 7). Again, the relative gap between the highest and the lowest SES group, and between the highest and the middle SES group, also increased with time for both males and females (Figure 8). The gap between the lowest and middle SES groups increased over time for both males and females (Figure 8).

\section{DISCUSSION}

During the last two decades, there has been increasing interest in the differences in health experienced by different socioeconomic groups. Socioeconomic health inequalities have become the focus of health sector efforts in many countries around the world. Socioeconomic inequalities in health are not only evident in mortality rates; they are evident at every stage of the life course. ${ }^{7}$

In trying to explain these socioeconomic health inequalities, it has become clear that social, physical, economic, and environmental factors are the most fundamental determinants of health. Government policies and initiatives that address education, housing, and employment opportunities, are likely to have a significant influence on these factors.

Evidence suggests that some of the risk factors for primary avoidable conditions are more prevalent in the lower SES groups than in the highest SES groups. For example, tobacco smoking, which is a risk factor for ischaemic heart disease and lung cancer, was more prevalent in the lower SES groups in NSW in 1994 and 1997-1998 than in the highest SES group. ${ }^{7,8}$ National data show that between 1980 and 1995 the prevalence of smoking among males decreased for all SES groups, ${ }^{8,9,10,11,12}$ but the smallest decrease occurred in the lowest SES group (defined as lower blue collar workers). Overweight and obesity, which are risk factors for ischaemic heart disease, were higher in the lower SES groups than the highest in 1994 and in 1997-1998. ${ }^{7,13}$ Excessive alcohol consumption (as measured by 'Heavy drinking days'), a risk factor for road 
traffic accidents, was significantly higher in the lowest SES group (39.5 per cent of those who drink occasionally or regularly) than in the highest SES group (32.8 per cent) in NSW in 1997-1998. ${ }^{13}$

As described in this article, the gradients in PAM that are seen with socioeconomic status also suggest that primary prevention strategies are much more effective in the highest SES group than in the middle and lowest SES groups. There is also international evidence to suggest that this is the case. ${ }^{7}$ This might be because people from lower SES groups have less access to preventive health services, because health promotion messages might be less appropriate to these groups and because lower SES groups face greater impediments that hinder behavioural change. ${ }^{3,7}$ Increasingly, health promotion messages are being designed to be more relevant to lower SES groups and culturally and linguistically diverse communities. ${ }^{16}$ Over time, this should lead to a greater decrease in PAM in the lower SES groups.

It is also of interest that, in 2000, rates of PAM are only slightly higher-six per cent higher for males and five per cent higher for females - in the lowest SES group than in the middle SES group, and that the relative gap between these groups has decreased slightly for males and has been almost constant for females between 1980 and 2000 for PAM. The exception to this is road traffic accidents, where the gap between the lowest and middle SES groups increased between 1980 and 2000. This may be due to an overrepresentation in the lower SES group of people from rural areas, where rates of road traffic accidents are significantly higher. ${ }^{4}$

\section{CONCLUSION}

To date, the call to reduce socioeconomic inequalities in health has mainly resulted in interventions targeted at the lowest SES group. PAM data and other health status ${ }^{4}$ data indicate that in many cases the greatest gap is between the highest SES group and the rest of the population (lowest and middle SES groups). This raises a number of issues for health policy development:

- the need to continue to target the lowest SES group to maintain its rate of improvement in PAM in the future;

- the need to develop programs that are aimed at reducing the gap between the rest of the population and the highest SES group.

The biggest gains in health across the population will be in improving health outcomes for both the middle and lowest SES groups. This analysis suggests that interventions that target smoking, other risk factors for cardiovascular disease, and road traffic accidents in these groups are likely to have the biggest impact on reducing inequalities in PAM.

Inter-sectoral action is required to identify and address the determinants of health inequalities.

In NSW, a Health and Equity Statement has been developed in an attempt to reduce health inequalities through engaging the health sector, the community and other government and non-government organisations. ${ }^{15}$

\section{REFERENCES}

1. Turrell G, Mathers C. Socioeconomic status and health in Australia. Med J Aust 2000; 172: 434-438.

2. Moore H, Jorm L. Measuring health inequalities in New South Wales. N S W Public Health Bull 2001; 12: 120-125.

3. Tobias M, Jackson G. Avoidable mortality in New Zealand, 1981-97. Aust N Z J Public Health 2001; 25: 12-20.

4. Public Health Division. The health of the people of New South Wales-Report of the Chief Health Officer 2002. Sydney: NSW Department of Health, 2002. www.health.nsw.gov.au/ public-health/chorep.

5. Australian Bureau of Statistics. 1996 Census of population and housing. Socioeconomic indexes for areas. ABS Catalogue no. 2039.0. Canberra: ABS, 1998.

6. Armitage P, Berry G, Matthews JNS. Statistical Methods in Medical Research, 4th Edition. Oxford: Blackwell Science, 2002.

7. Turrell G, Oldenburg B, McGuffog I, Dent R. Socioeconomic determinants of health: towards a national research program and a policy and intervention agenda. Canberra: AusInfo, 1999.

8. Hill D, Gray N. Patterns of tobacco smoking in Australia, Med J Aust 1982; 1: 23-25.

9. Hill D, Gray N. Australian patterns of tobacco smoking in 1986. Med J Aust 1988; 149: 6-10.

10. Hill D, White V, Gray N. Australian patterns of tobacco smoking in 1989, Med J Aust 1991; 154: 797-801.

11. Hill D, White V. Australian adult smoking prevalence in 1992. Aust J Public Health 1995; 19: 305-308.

12. Hill D, White V, Scollo M. Smoking behaviours of Australian adults in 1995: Trends and concerns. Med J Aust 1998; 168: 209-213.

13. Harris E, Sainsbury P, Nutbeam P (editors). Perspectives on health inequity. Sydney: Australian Centre for Health Promotion, 1999.

14. Public Health Division. Report on the 1997 and 1998 NSW Health Surveys. Sydney: NSW Department of Health, 2000. www.health.nsw.gov.au/public-health/nswhs/hsindex.htm.

15. Policy Division. NSW Health and Equity Statement. Sydney: NSW Department of Health, (unpublished).

16. Public Health Division. Healthy People 2005-New directions for public health in NSW. Sydney: NSW Department of Health, 2000. 


\section{FIGURE 1}

PRIMARY AVOIDABLE MORTALITY, NSW, 1980-2000

(a) Males

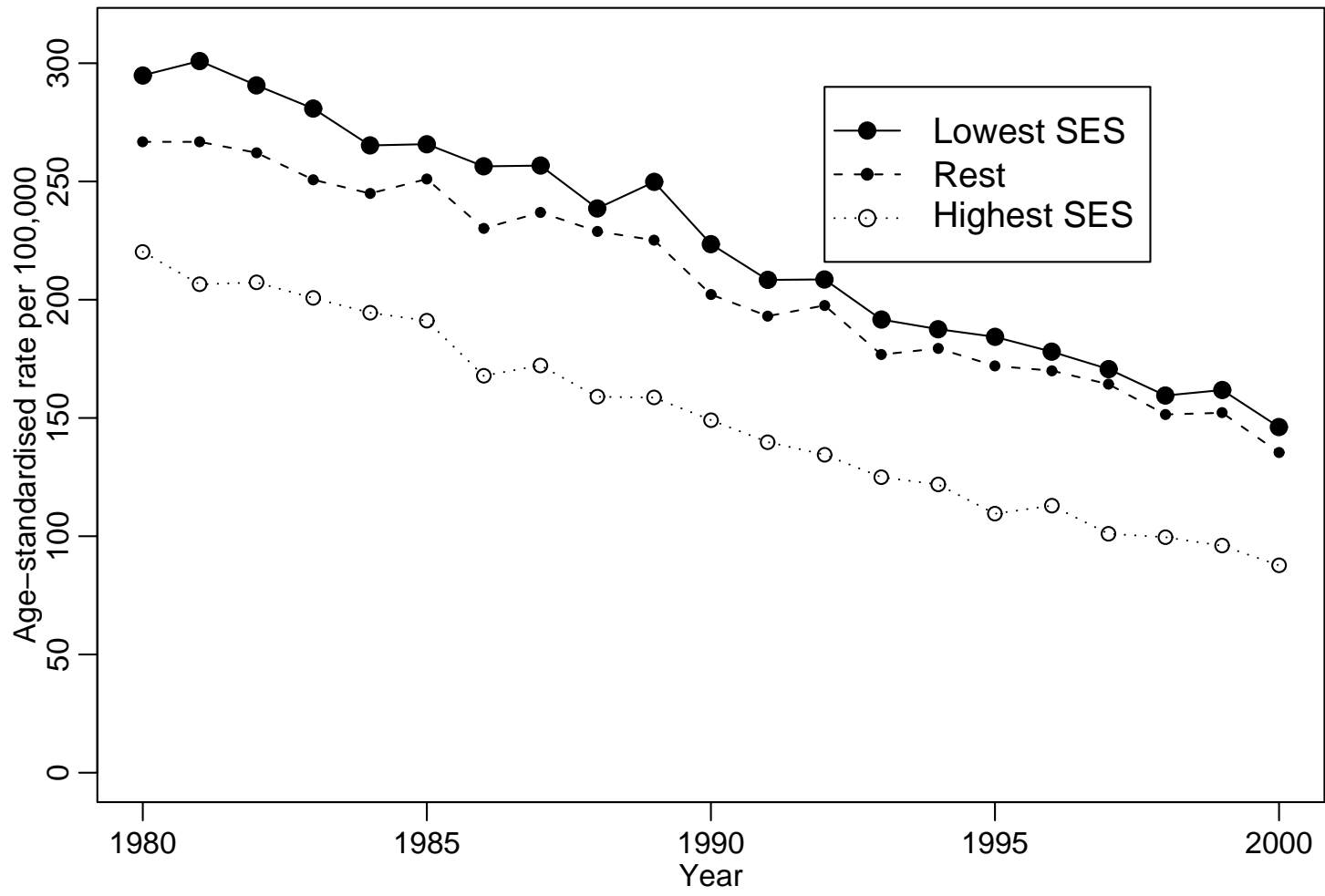

(b) Females

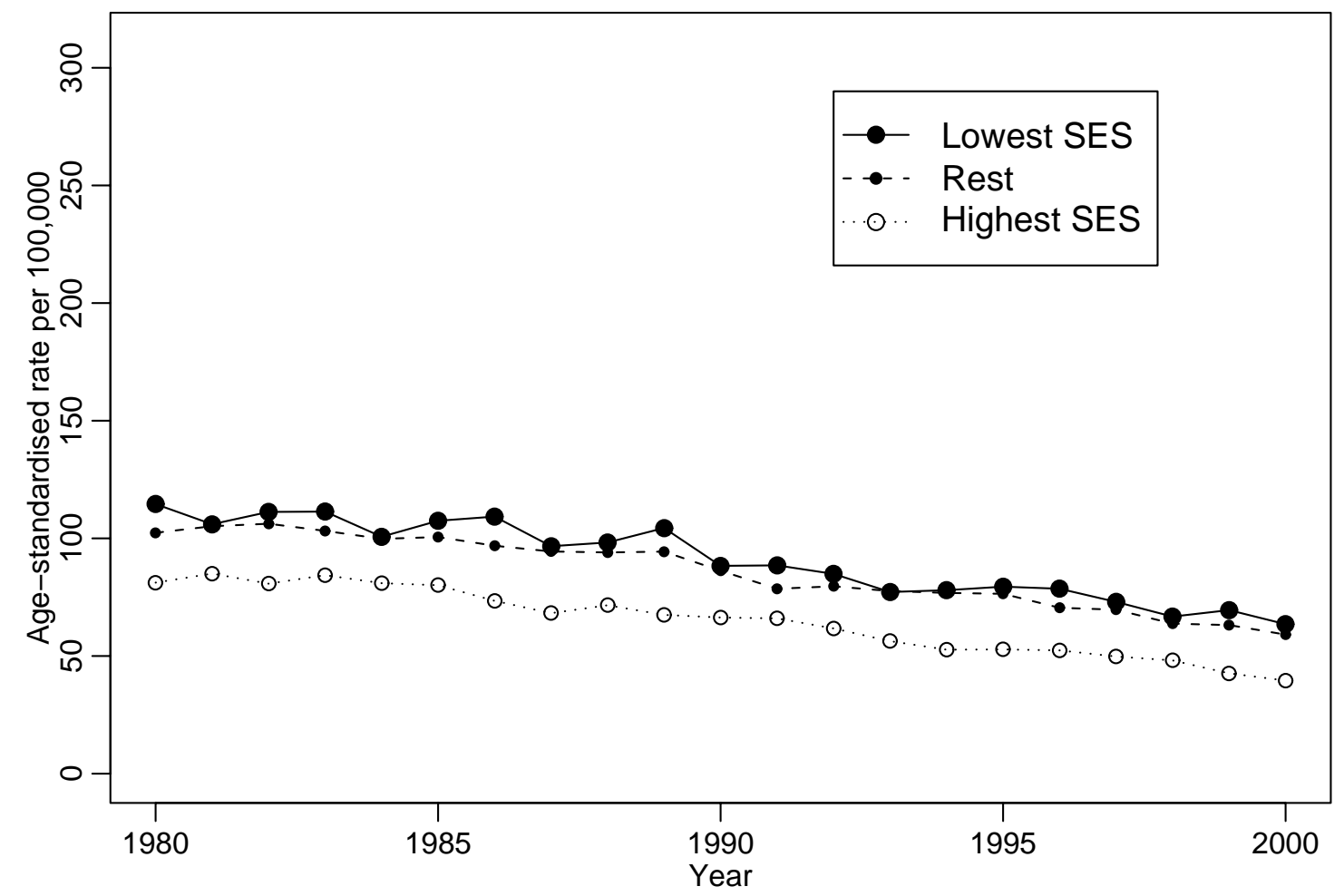




\section{FIGURE 2}

GAPS IN PRIMARY AVOIDABLE MORTALITY, NSW, 1980-2000

(a) Males

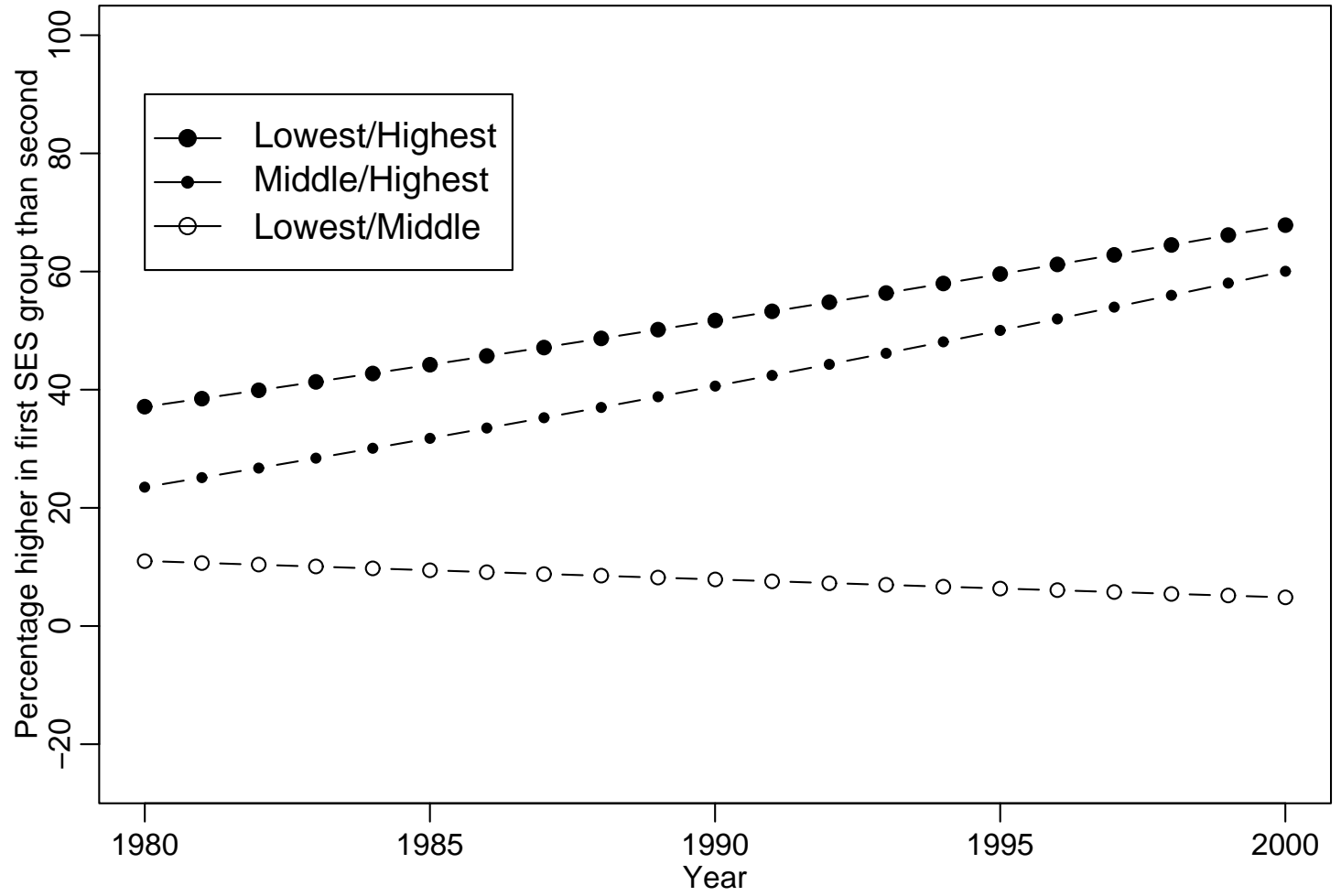

(b) Females

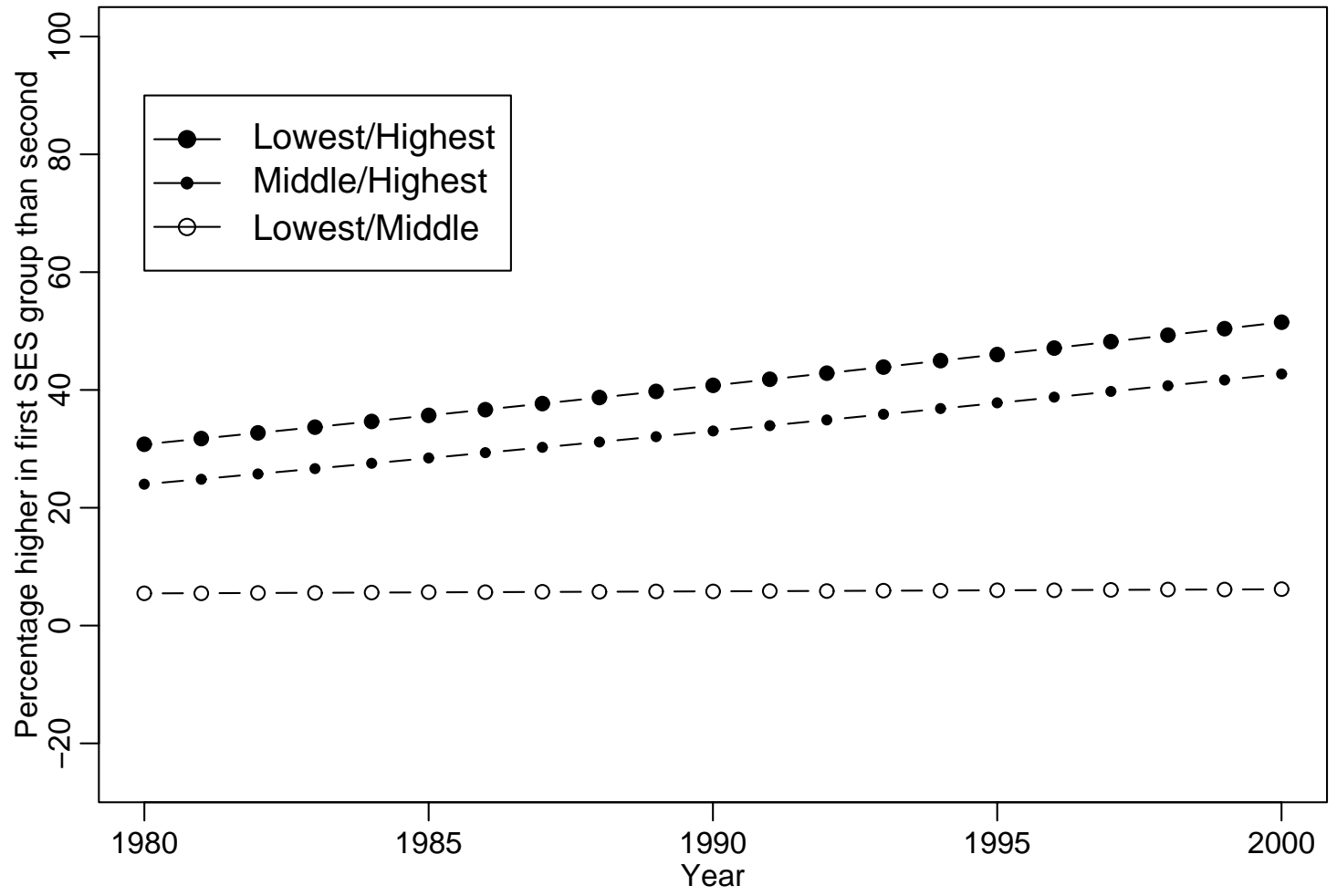


FIGURE 3

PRIMARY AVOIDABLE MORTALITY DUE TO HEART DISEASE, NSW, 1980-2000

(a) Males

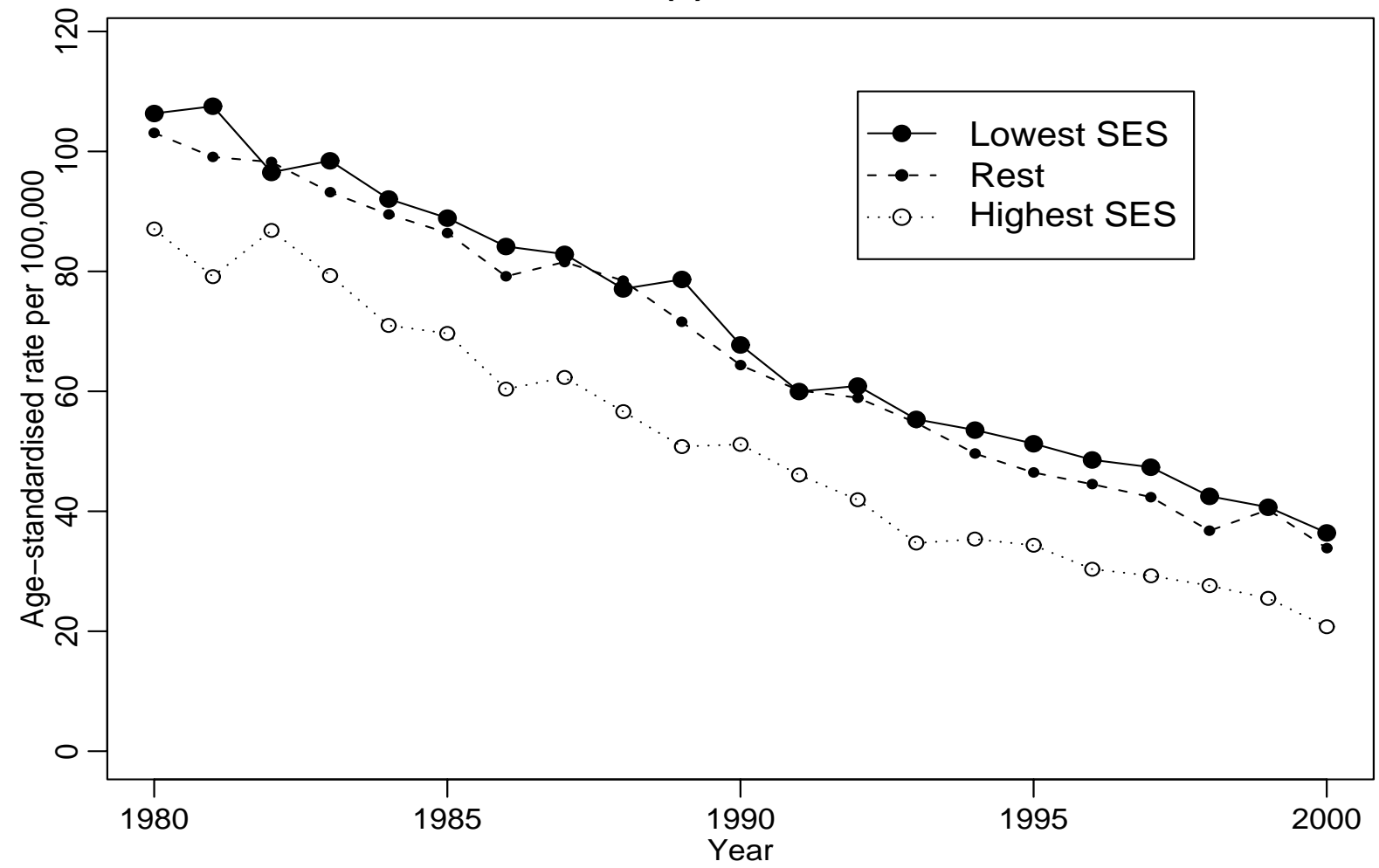

(b) Females

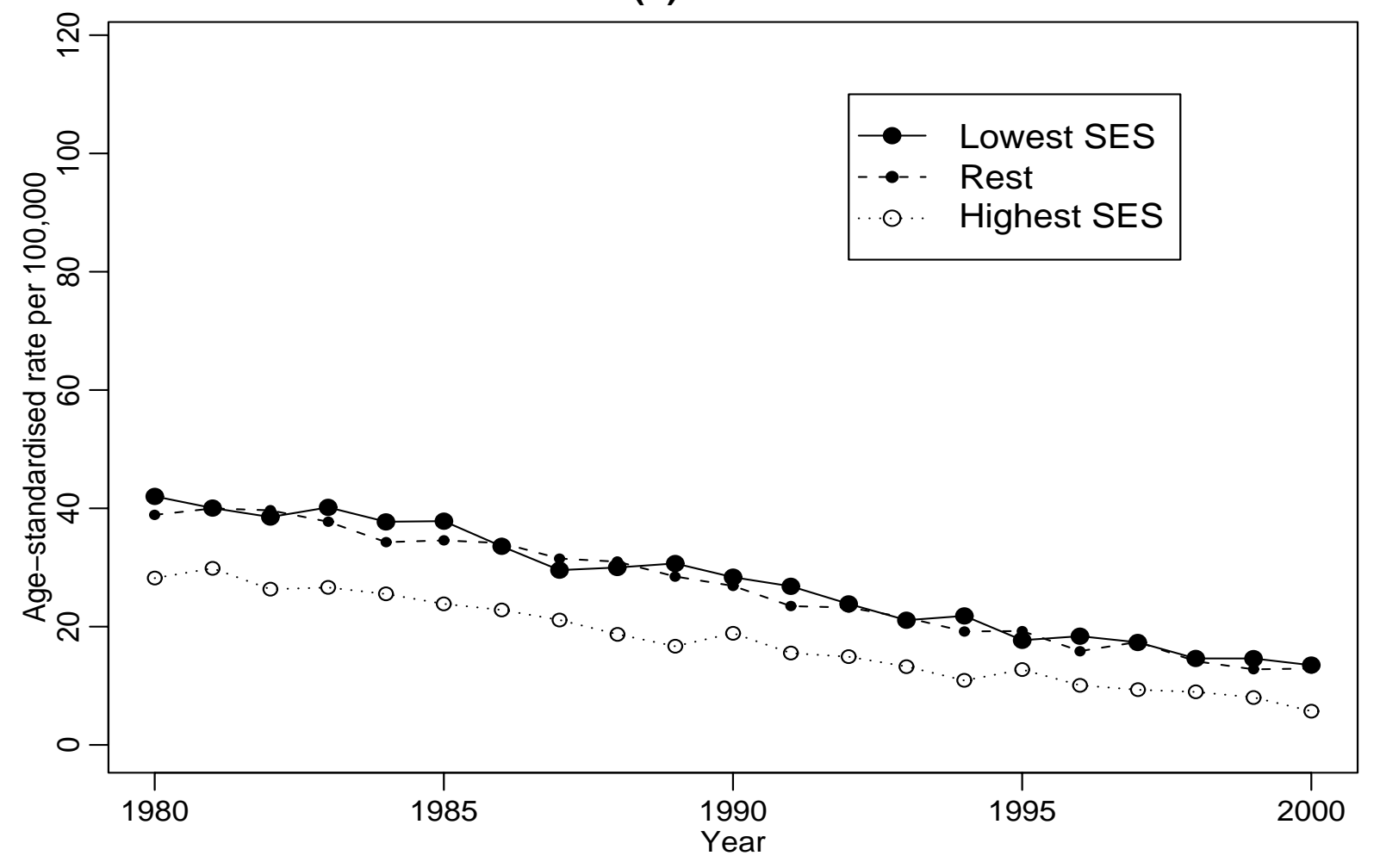




\section{FIGURE 4}

GAPS IN PRIMARY AVOIDABLE MORTALITY DUE TO HEART DISEASE, NSW, 1980-2000

(a) Males

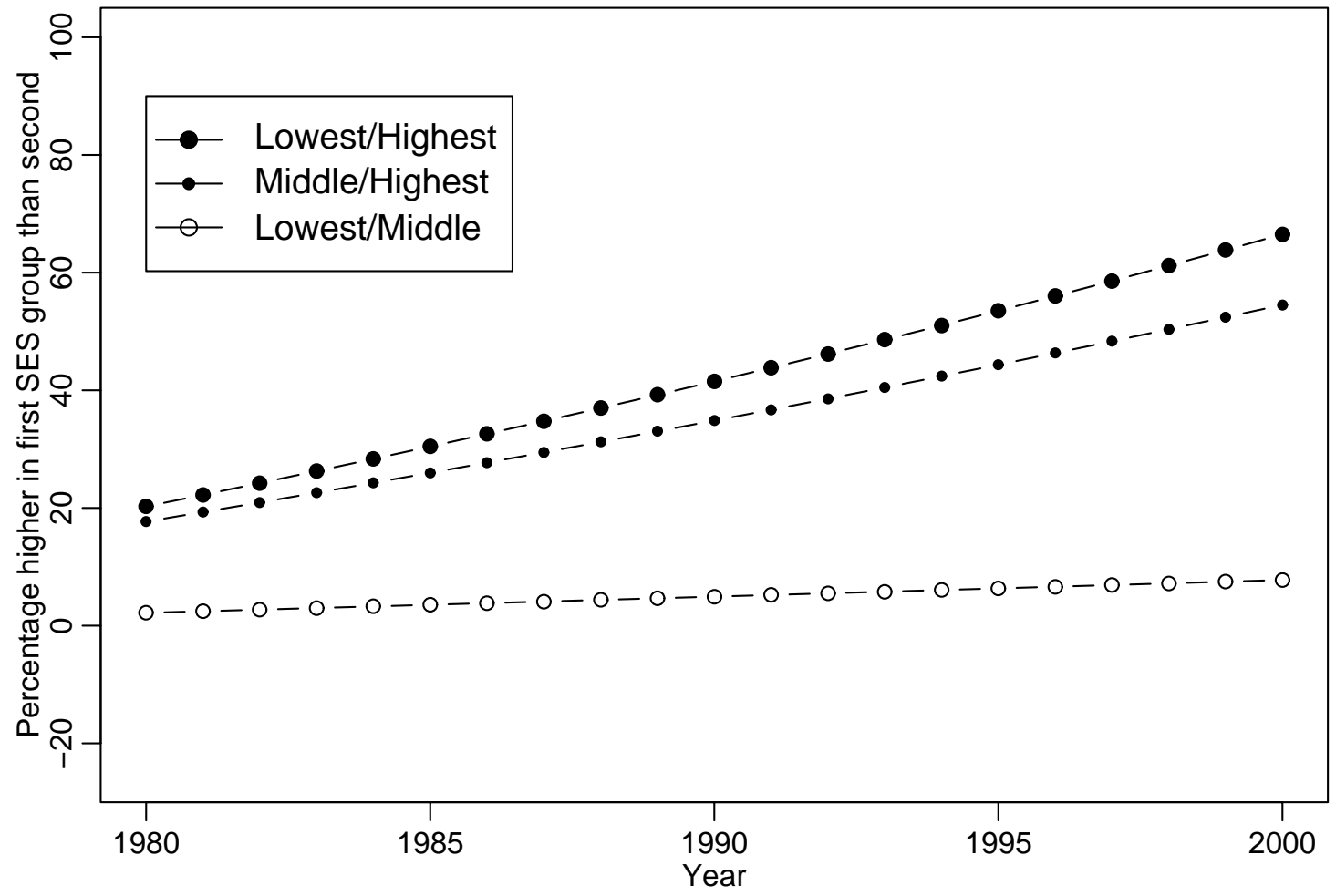

(b) Females

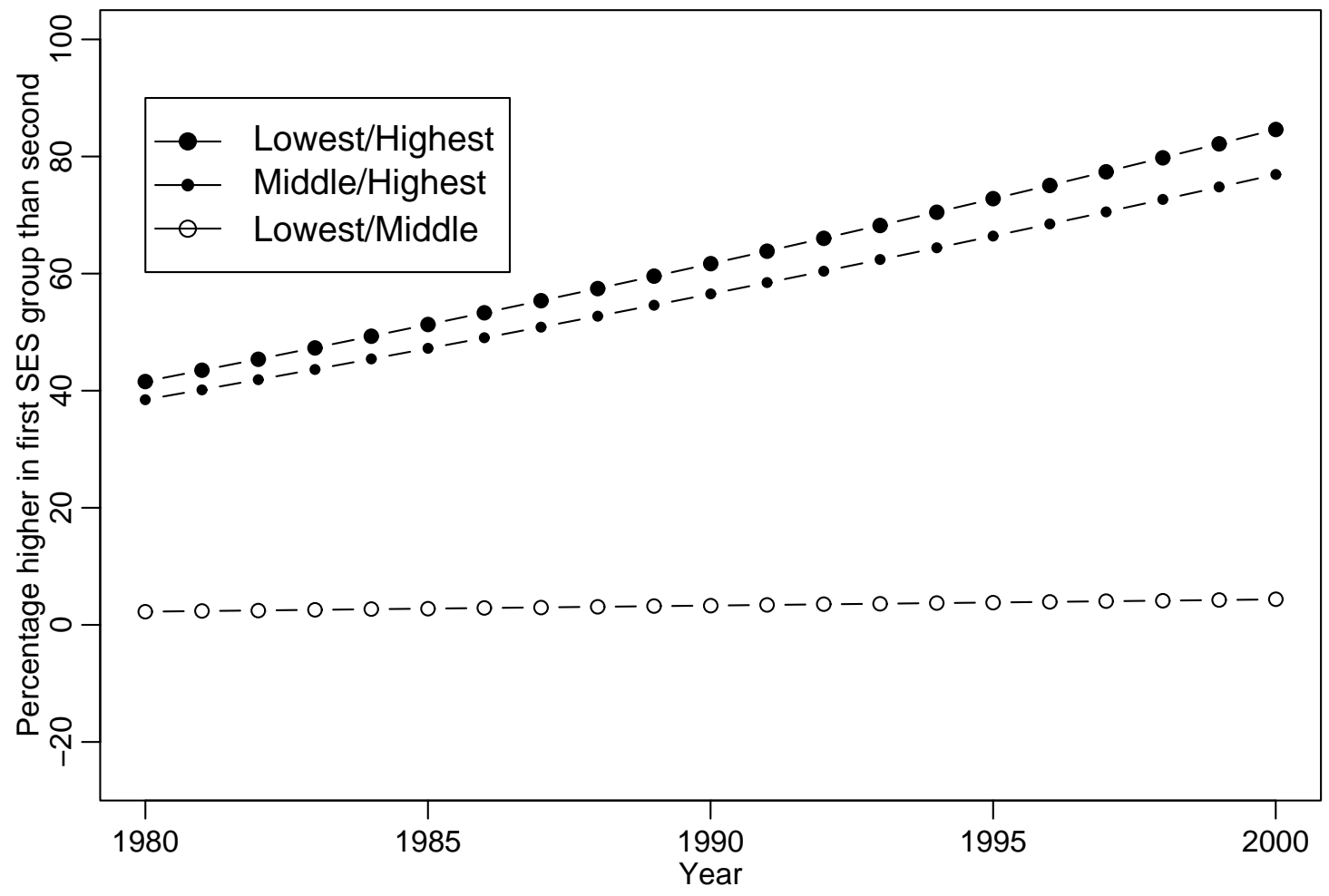




\section{FIGURE 5}

PRIMARY AVOIDABLE MORTALITY DUETO LUNG CANCER, NSW, 1980-2000

(a) Males

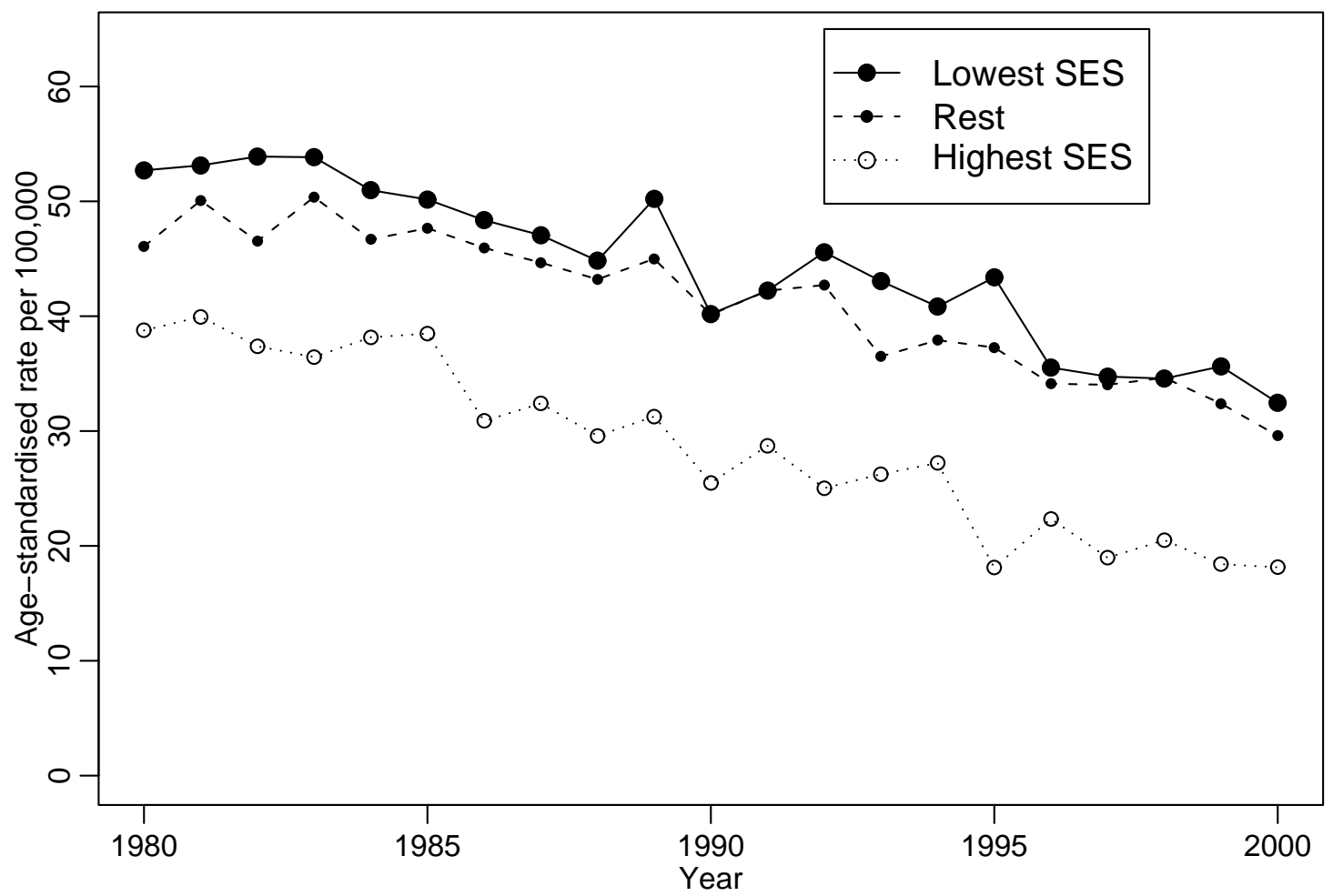

(b) Females

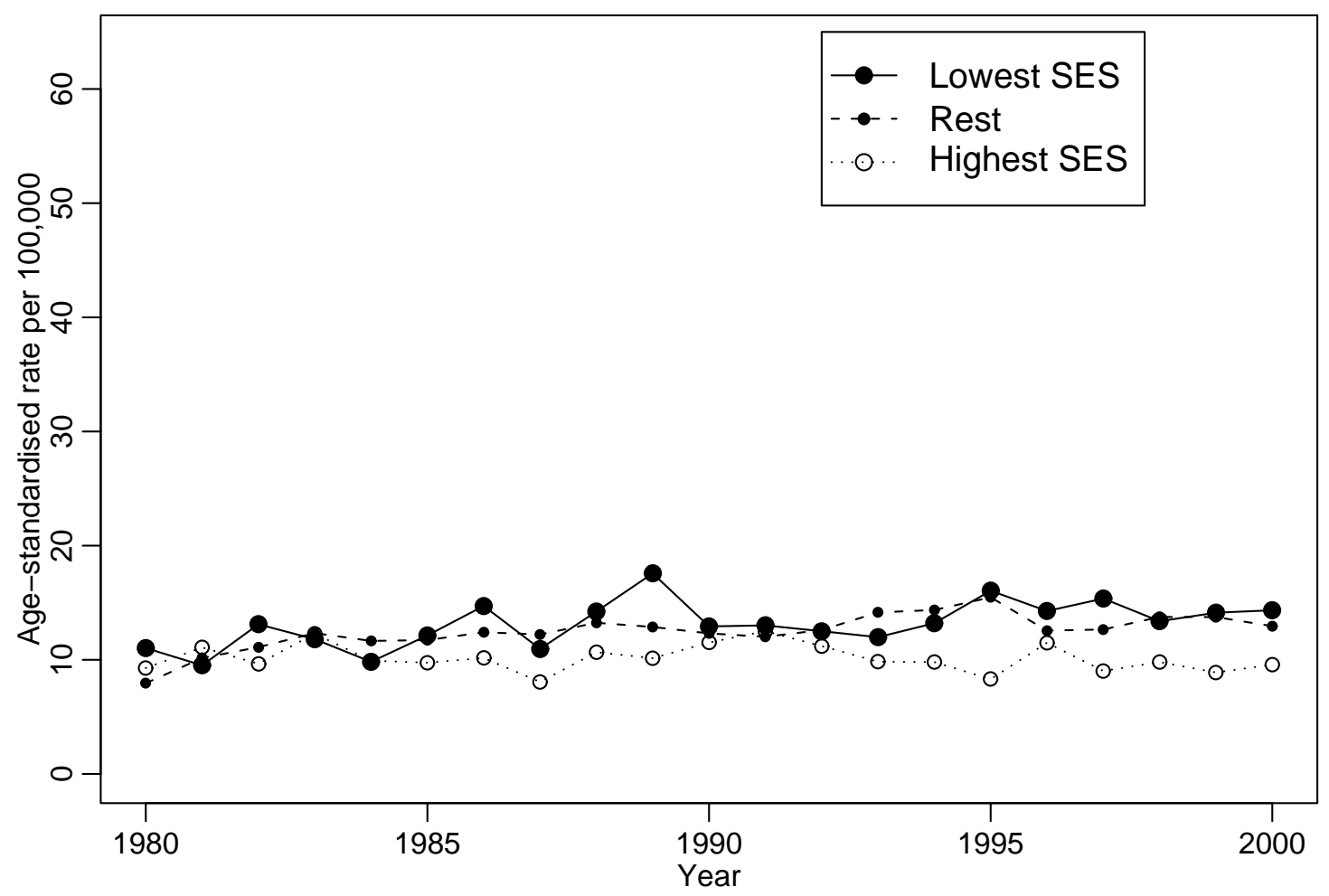




\section{FIGURE 6}

GAPS IN PRIMARY AVOIDABLE MORTALITY DUE TO LUNG CANCER, NSW, 1980-2000

(a) Males

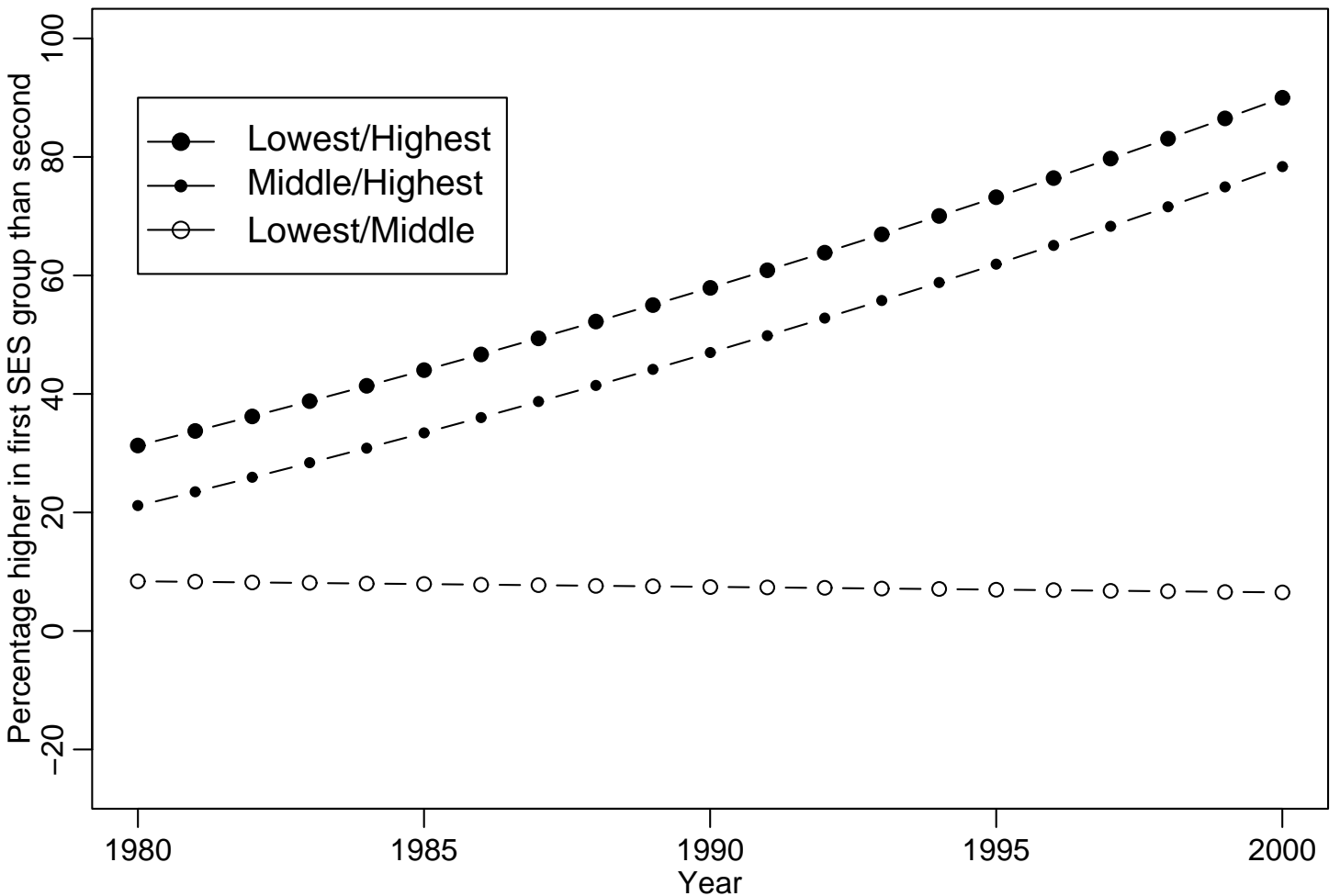

(b) Females

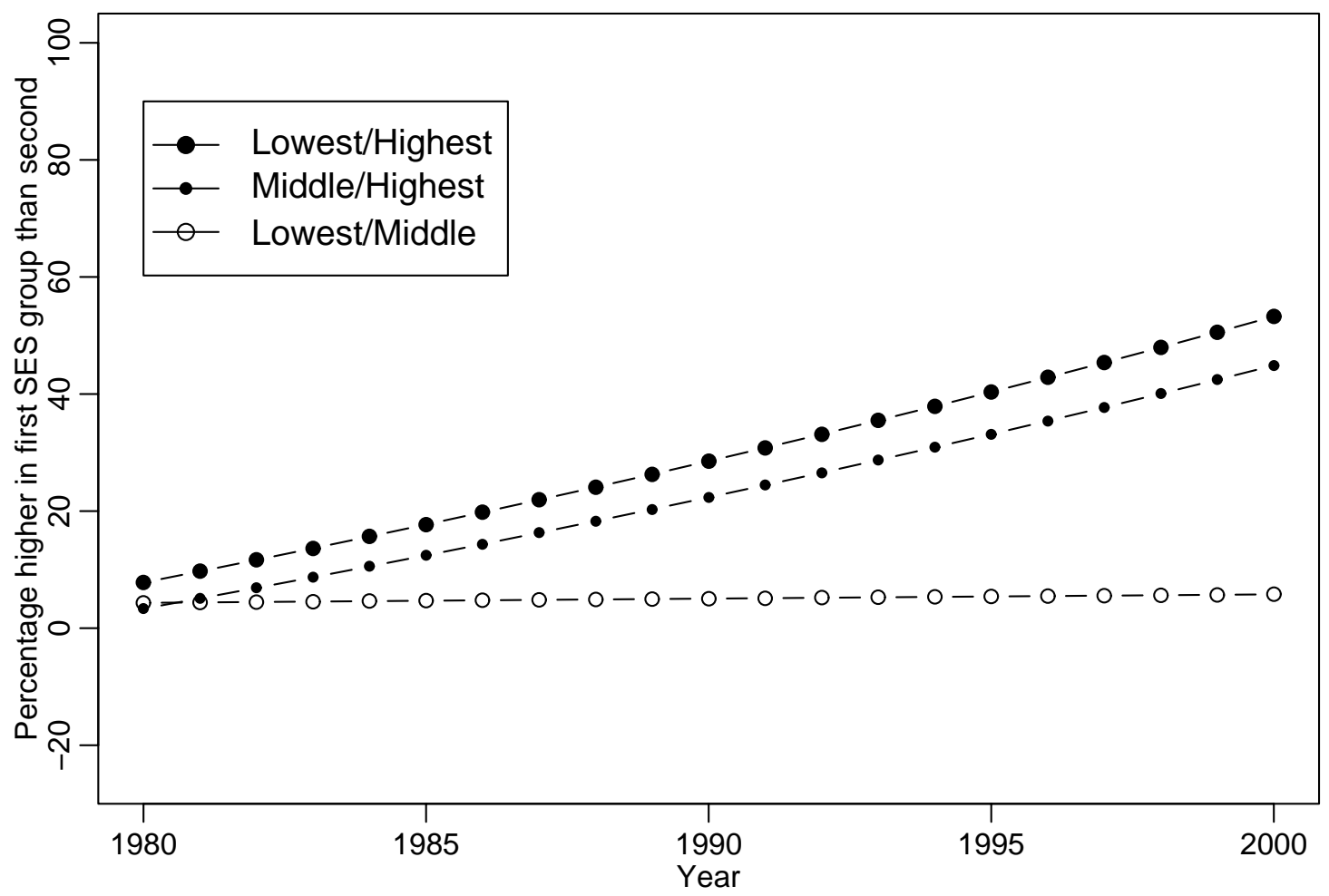




\section{FIGURE 7}

PRIMARY AVOIDABLE MORTALITY DUE TO ROADTRAFFIC ACCIDENTS, NSW, 1980-2000

(a) Males

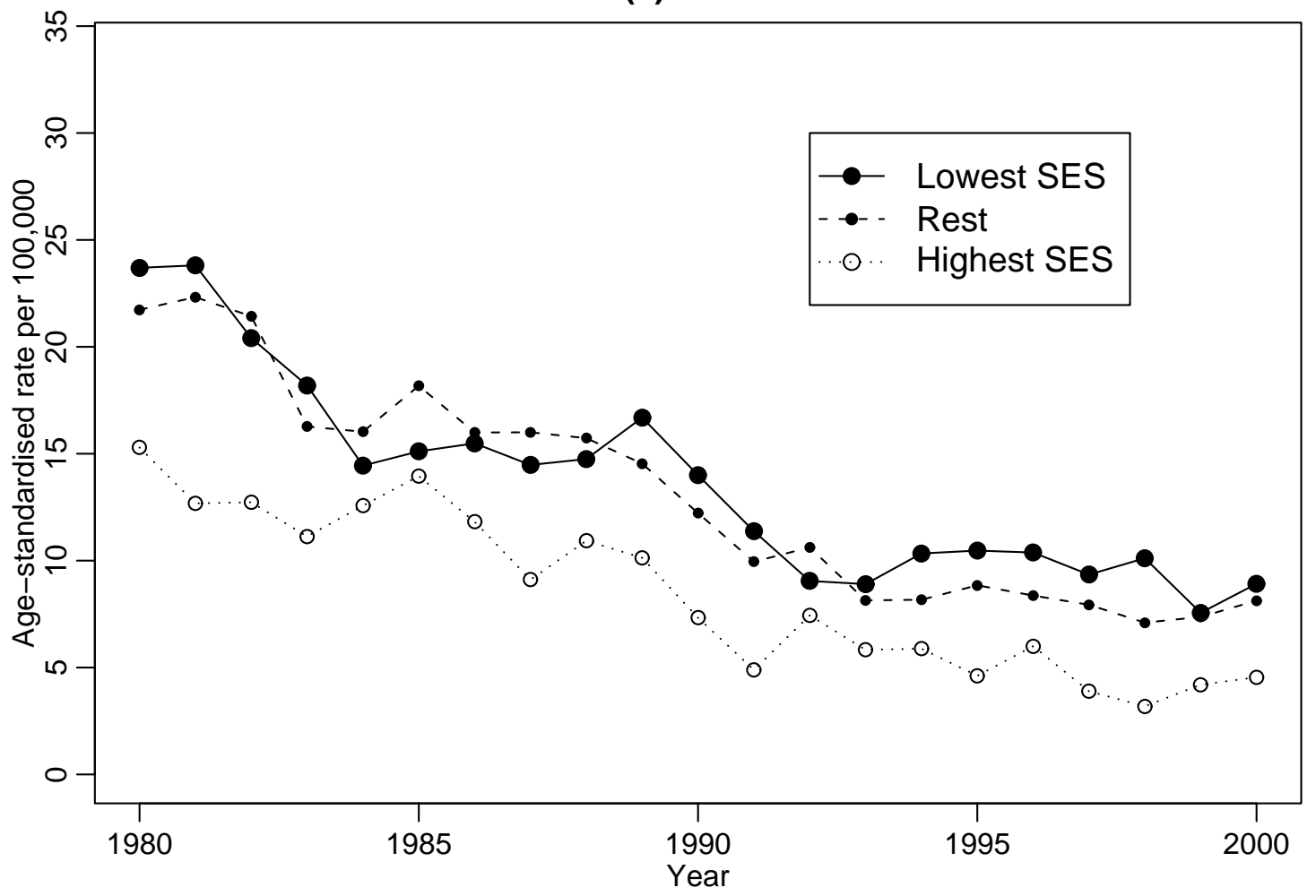

(b) Females

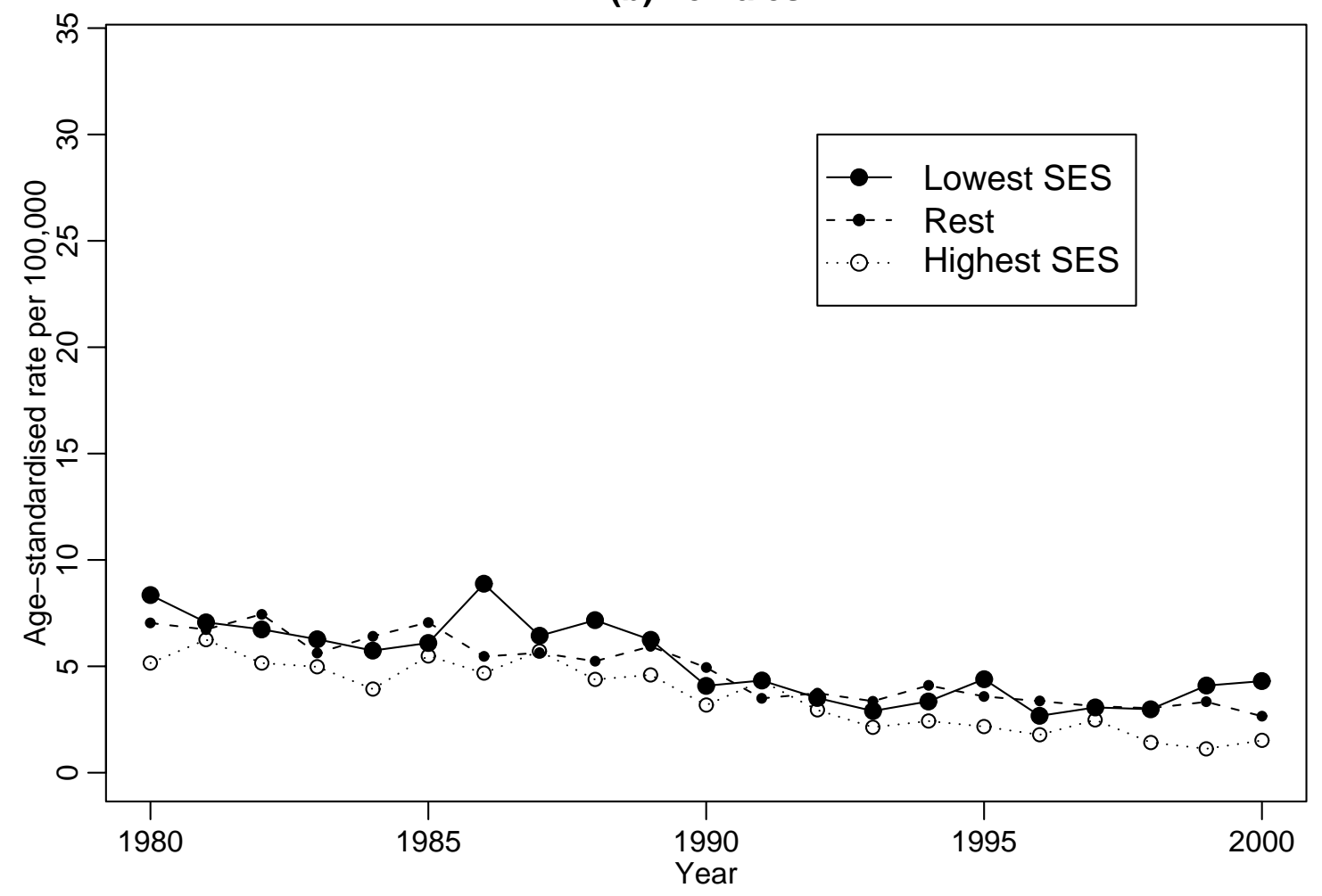




\section{FIGURE 8}

GAPS IN PRIMARY AVOIDABLE MORTALITY DUE TO ROADTRAFFIC ACCIDENTS, NSW, 1980-2000

(a) Males

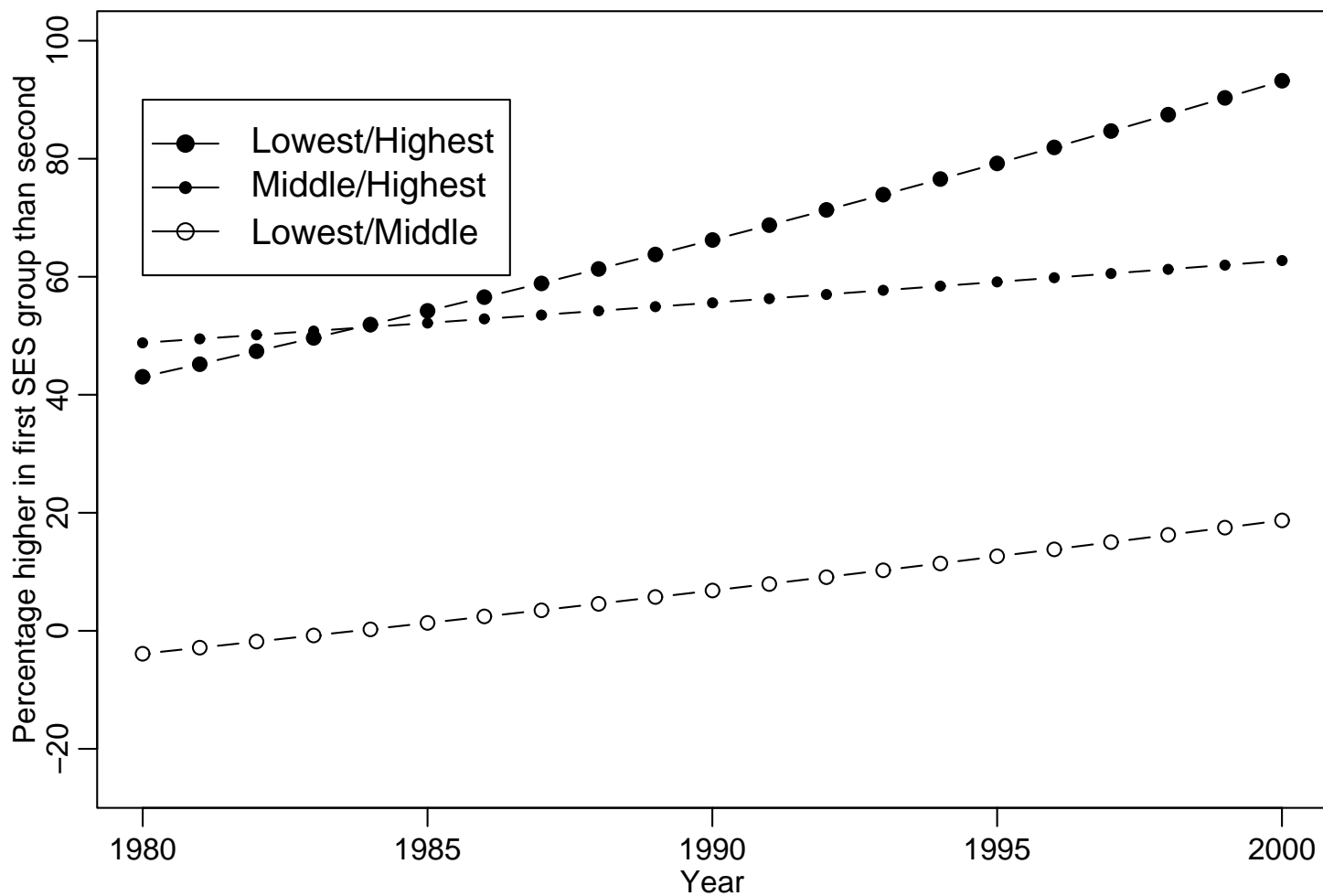

(b) Females

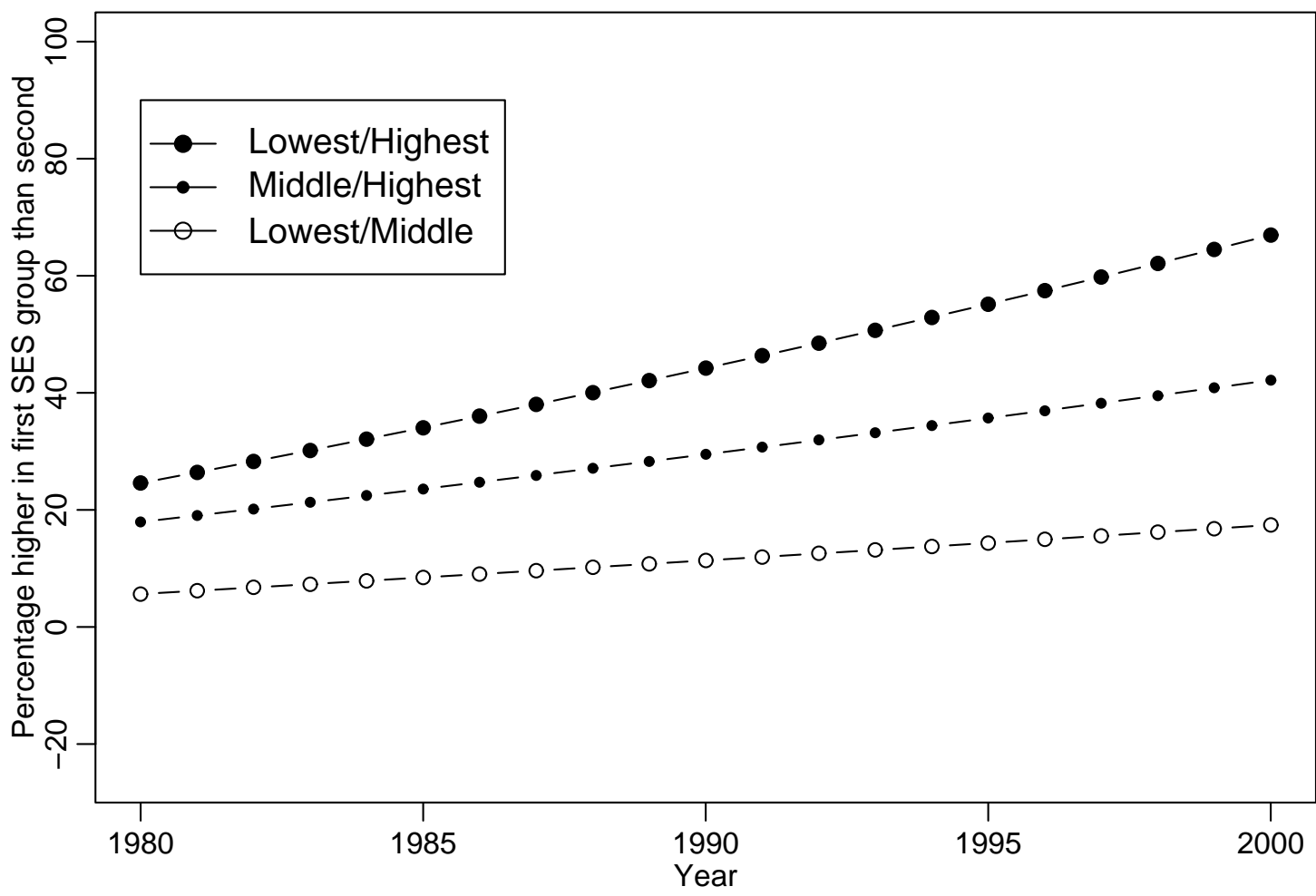

